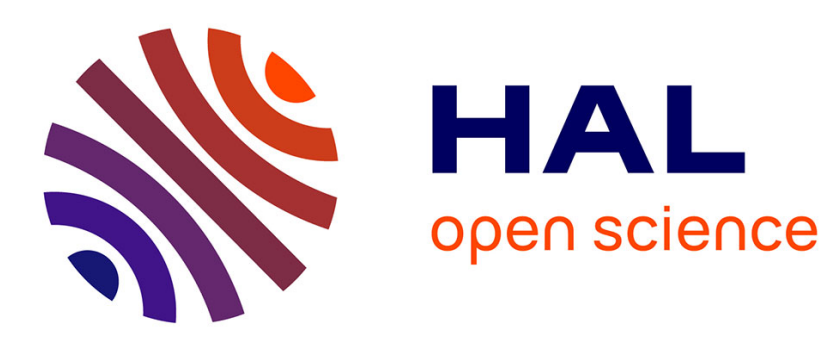

\title{
Uncovering the Role of Glycogen in Brown Adipose Tissue
}

\author{
Alicia Mayeuf-Louchart
}

\section{To cite this version:}

Alicia Mayeuf-Louchart. Uncovering the Role of Glycogen in Brown Adipose Tissue. Pharmaceutical Research, 2021, 38, pp.9-14. 10.1007/s11095-020-02979-6 . inserm-03121019

\section{HAL Id: inserm-03121019 https://www.hal.inserm.fr/inserm-03121019}

Submitted on 26 Jan 2021

HAL is a multi-disciplinary open access archive for the deposit and dissemination of scientific research documents, whether they are published or not. The documents may come from teaching and research institutions in France or abroad, or from public or private research centers.
L'archive ouverte pluridisciplinaire HAL, est destinée au dépôt et à la diffusion de documents scientifiques de niveau recherche, publiés ou non, émanant des établissements d'enseignement et de recherche français ou étrangers, des laboratoires publics ou privés. 


\title{
Uncovering the role of glycogen in brown adipose tissue
}

\author{
Alicia Mayeuf-Louchart \\ Univ. Lille, Inserm, CHU Lille, Institut Pasteur de Lille, U1011- EGID, F-59000 Lille, France \\ Correspondance : alicia.mayeuf-louchart@inserm.fr
}

\begin{abstract}
The presence of glycogen in the brown adipose tissue (BAT) has been described 60 years ago. However, the role of this energetic storage in brown adipocytes has been long time underestimated. We have recently shown that during brown adipocyte differentiation in the embryo, glycogen accumulates and is degraded by glycophagy, a dynamic essential for lipid droplets biogenesis. Recent studies have shown that the storage and degradation of triglycerides in BAT are not essential for the activation of BAT in response to cold exposure in adults, and that glycogen can compensate for their absence. In this review, we report the recent advances related to the importance of glycogen in brown adipocytes.
\end{abstract}

\section{Introduction}

Cold exposure and hyperphagia leads to non-shivering thermogenesis by the BAT. For a long time, it was believed that BAT was only present in newborns and young, but not in adults in non-hibernating animals. However, several studies have demonstrated the presence of a functional BAT in adult humans, which can be activated by cold exposure (13). Human BAT shares common characteristics with the well-studied interscapular BAT in mice, at cellular and molecular levels.

One of the main characteristics of BAT, as well as white adipose tissue (WAT), is the presence of lipid droplets (LD) in the cytoplasm. WAT and BAT are different in many ways, both in terms of metabolism and embryonic origin (reviewed in (4)). While WAT is involved in lipid storage and fatty-acid release during fasting, BAT produces heat. Non-shivering thermogenesis is mediated by the stimulation of $\beta$-adrenergic receptors in brown adipocytes. The specific presence of the uncoupling protein, UCP1, located in the inner membrane of the mitochondria of brown adipocytes serves to decouple the mitochondrial respiratory chain 
from ATP production, involved in heat production. When BAT is stimulated by exposure to cold, for example, it becomes metabolically active because thermogenesis requires energy substrates. In this review, we will focus on the latest research on energy storage and use in BAT. Contrary to what might be expected from a lipid-rich tissue, the storage of carbohydrates in the form of glycogen and its metabolism play an important role in BAT, changing our conventional view of this tissue.

\section{Lipolysis during BAT activation}

LDs are cytoplasmic organelles containing lipids stored as triglycerides (TG) and cholesterol. They are surrounded by a single layer of phospholipids, in which a number of specific proteins such as perilipins are incorporated. While white adipocytes contain a single LD occupying the majority of the cytoplasm, brown adipocytes contain a multitude of small LDs. This difference is explained at the molecular level by the involvement of different factors that specifically control LD formation in white and brown adipocytes. For example, in white adipocytes, FSP27 $\alpha$ is expressed at the surface of two LD and allows their fusion, therefore promoting the formation of larger LDs. In the brown adipocytes, the expression of the FSP27 $\beta$ isoform is responsible of the inhibition of LD fusion, resulting in the presence of multiple small LDs (5). Many proteins on the surface of LD are involved in lipolysis, such as lipases and lipase regulators, which allow the formation of free fatty acids (FA) that are available when needed.

After exposure to cold, plasma glycerol increases. This observation led to the conclusion that the majority of calories used come from fat oxidation (6). In addition, the lack of increase in plasma FFAs during cold exposure indicates that hydrolyzed TGs have been metabolized by cells (7). In humans, the activation of BAT by short-term cold exposure accelerated plasma TG clearance through increased lipid absorption in BAT (8). Moreover, the niacin-induced inhibition of intracellular lipolysis impairs cold-induced thermogenesis (9). Altogether, these results therefore unveil the importance of lipolysis in BAT during cold exposure. 
In order to better understand the underlying mechanisms, many studies have analyzed the consequences of lipases deletion in different mouse models. In constitutive adipose triglyceride lipase (ATGL)-deficient mice, BAT contains larger LDs and its weight is increased (10). These mice are unable to adapt to cold thus confirming the importance of lipolysis for BAT activity. These results also suggest that other lipases, such as HSL, cannot compensate for the absence of ATGL, which has been confirmed by other studies (11-13). The inability to mobilize lipid stores in constitutive ATGL-deficient mice increases the use of glucose as an energy source. However, this is not sufficient to withstand exposure to cold and these mice die prematurely due to cardiac dysfunction (10).

The inability to respond to cold was initially attributed to defective lipolysis of BAT, until mice deficient in ATGL, specifically in adipocytes, were then generated. The absence of ATGL, in both white and brown adipocytes, induces the conversion of BAT into a WAT-like tissue and also impairs cold-induced thermogenesis (14). But wat is the specific role of ATGL in brown adipocytes? Later studies have then discriminated the specific role of lipolysis in WAT and BAT, based on mouse models in which ATGL or its activator CGI-58 (LDassociated protein that acts as a coactivator of ATGL) have been specifically deleted in BAT. Contrary to what might have been expected, the results show that brown adipocyte lipolysis is not essential for BAT, which is still able to adapt to cold exposure $(12,15)$. However, in absence of FA provided from food, lipolysis is required in the WAT to release the fuel substrates indispensable for thermogenesis. Lipolysis in WAT also promotes insulin secretion, which is essential for efficient lipid and glucose uptake by the BAT (16). In addition, the release of long chain FA by the WAT activates the nuclear receptor HNF4 $\alpha$ in the liver, which induces hepatic carnitilation. In turn, plasmatic acylcarnitine stimulates BAT thermogenesis (17). Altogether, these studies unveil the importance of organ crosstalk through the production of hormones and metabolites for BAT thermogenesis.

As previously shown in constitutive ATGL-deficient mice, the inhibition of lipolysis specifically in BAT reprograms this tissue to combust more glucose, as indicated by the increase of Glut1 expression and glucose uptake in CGI-58-KO mice during cold exposure 
(15). As a consequence, a bolus of glucose only induces a minor increase of blood glucose during cold exposure and this is associated with a better metabolic profile. On the contrary, in humans, inhibition of intracellular lipolysis by the administration of niacin alters glucose absorption in BAT (9). Compared to mice studies, niacin supplement is not specific to BAT and the inhibition of lipolysis in other organs can explain these differences. In addition, differences in BAT activity between humans and rodents have been reported. For instance, while in rodents BAT thermogenesis is mediated by $\beta_{3}$-adrenergic receptor, in humans, this is the $\beta_{2}$-adrenergic receptor that is involved in lipolysis and thermogenesis (18).

Overall, these studies show that lipolysis is essential during cold exposure but that it is dispensable in brown adipocytes. This is due compensation mechanisms between the use of intracellular triglyceride stores, glucose and circulating FAs. Circulating FFA and triglyceride rich lipoproteins (TRL) are two extracellular sources of FAs metabolized by the BAT. Different FFA transporters are involved in the absorption of FFA such as CD36, while the uptake of FAs from TRL requires the activity of the lipoprotein lipase (LPL) (19). The LPL is expressed and secreted by brown adipocytes and its expression increases in BAT following cold exposure in rodents (8) and humans (20). Inhibition of LPL activity by the specific inhibitor tetrahydrolipstatin significantly affects the uptake of FA into brown adipocytes under cold conditions (8). In adipocyte-specific LPL knockout mice, the activity of BAT is not affected. This is probably due to the compensatory increase of glucose uptake and de novo lipogenesis (21). In conclusion, there is a strong metabolic flexibility in the use of different energetic substrates by BAT despite the fact that brown adipocytes have their own energy reserves in the form of LD (Figure 1). This raises the question of the role of these TG stored in LD in BAT. Are they degraded by other mechanisms during BAT activation or are they not essential for BAT?

\section{Which role for lipid droplets in BAT?}


Cold exposure has been shown to activate lipophagy in BAT, providing an alternative way to the cytosolic lipases ATGL and HSL for the degradation of TG (22). However, a recent study has demonstrated that LD are not essential in BAT for thermogenesis, thanks to a mouse model in which the two DGAT (Aacyl CoA:diacylglycerol acyltransferase) enzymes, DGAT1 and DGAT2, have been specifically deleted in mature brown adipocytes, through the expression of $U c p 1^{\text {Cre }}$ (23). DGATs are enzymes required for TG synthesis and their absence therefore impairs the storage of lipids and the formation of LD (24). Despite the absence of LD in DGAT1/2 knock-out (KO) mice, temperature is maintained in acute or chronic cold exposure. Which energetic substrates do they use? In the two previous studies on ATGL-deficient mice specifically in BAT $(12,15)$, it was shown that brown adipocytes use glucose and FAs from the diet or from their release by WAT. This is also the case in this study, as shown indirectly by the reduction in plasma TG and glucose. However, authors also show that glycogen compensates for the lack of lipid reserves. Indeed, at room temperature, BAT-specific DGAT1/2 KO mice contain five times more glycogen than the BAT of control mice (23). This excess glycogen is consumed by BAT during cold exposure, since the difference in glycogen content between control and KO mice disappeared after 6 hours of cold exposure.

We have recently shown that during embryonic development, LD are formed before Ucp1 expression (25). Consequently, by using the $U_{c p} 1^{\text {Cre }}$ for deletion of Dgat1/2 deletion, Chitraju and colleagues did not abrogate LD biogenesis in the embryo. The KO neonates probably consumed their TG during their first exposure to cold but were unable to re-form it afterwards. While this study shows that glycogen can substitute for LD during cold exposure, additional mouse models are needed to determine the role of LD at birth, during the first cold exposure of life, when the presence of glycogen has also been described $(26,27)$.

\section{Long-standing evidence of the presence of glycogen in BAT}

The ${ }^{18}$ FDG-PET/CT scanning technique is used to detect active BAT, illustrating how BAT is a large consumer of glucose. Different studies based on cultured brown adipocytes 
treated with siRNA or genetic mouse models deficient in genes encoding glucose transporters or glycolytic enzymes have shown the requirement of glucose for BAT thermogenesis (reviewed in $(28,29)$ ). In addition, numerous studies have highlighted that the glucose is stored as glycogen in BAT. Already, in the 1950/60s, the presence of glycogen granules was described in BAT by electron microscopy $(26,27)$. In 1952, Fawcett et al. showed in adult rats that BAT is composed of a lower fat content and a higher glycogen content than WAT (Fawcett 1952), and these results were subsequently confirmed in rabbits (7). It was also reported that glycogen is produced from glucose in BAT in a same way as it occurs in skeletal muscle (30).

The presence of glycogen in adult BAT has also been reported. During the reacclimation period at neutral temperature following 3 weeks of cold exposure, there is a transient increase in glycogen content (31). Then the amount of glycogen decreases again 3 weeks afterwards, but is still higher than before cold exposure. This glycogen accumulation depends on the activation of Akt and the inactivation of GSK-3, which improves glycogen synthesis (32). The same concept of a transient increase of glycogen has also been described for refeeding after fasting (33). This transient accumulation of glycogen in the BAT during re-feeding is followed by an increase in the LD in brown adipocytes $(34,35)$. It has been proposed that the rapid degradation of glycogen could provide glycerol-3-phosphate, a monoglyceride precursor, thereby replenishing lipid stocks $(34,35)$.

At a molecular level, the expression of two key enzymes for glycogen production, Glycogen synthase 1 (Gys1) and 2 (Gys2) are upregulated during cold exposure in BAT. This is accompanied by an increase in the expression of the Glycogen Phosphorylase $L$ (Pygl) involved in glycogen degradation (36). Gys and Pygl expressions are also upregulated in vitro upon $\beta$-adrenergic stimulation, which activates brown adipocytes (36). As far as we know, the function and importance of glycogen dynamics have never been studied in adult brown adipocytes. However, all of these studies suggest that the degradation of glycogen, which is transiently accumulated in brown adipocytes, provides the substrates required for de novo lipogenesis and LD replenishment. 


\section{Importance of glycogen in LD biogenesis during brown adipocyte differentiation}

We have recently shown that glycogen plays an important role in the development of BAT (25). During brown adipocyte differentiation, the glycogen appears at 14.5 days of embryogenesis (E14.5), before the formation of LDs that form in the immediate vicinity of glycogen clusters as early as 15.5 . From E15.5 to E18.5, the amount of glycogen decreases as the size of the LDs increases (Figure 2). This implies that, at the end of embryonic development, the fetus has numerous large LDs that can be used at birth. The requirement of glycogen for LD formation has been demonstrated using Gys1KO embryos in which the deletion of glycogen synthase 1 completely blocks LD formation. Similar results were obtained in human preadipocytes treated with siRNA for Gys1.

In this study, we also showed that glycogen degradation is essential for this process. It occurs through an autophagy-related mechanism named glycophagy. Glycophagy involves the protein STBD1 (Starch binding domain protein 1) that links glycogen and interacts with GABARAPL1 (GABA Type A Receptor Associated Protein Like 1) at the surface of the glycophagosome (37) (Figure 2). The fusion of the glycophagosome with the lysosome induces the degradation of glycogen into glucose-1-Phosphate by the acid $\alpha$-glucosidase (GAA) enzyme. The inhibition of autophagy and the knocking down of Stbd1 in primary brown adipocytes impairs LD biogenesis in embryonic brown adipocytes. Overall, our results show that glycogen production and degradation are essential for the biogenesis of LD in brown adipocytes (25). Interestingly, in white adipocytes, glycogen also accumulates during differentiation but the deletion of Glycogen synthase 1 does not affect LD formation (25). Electron microscopy pictures indicates that the close proximity of glycogen and LD found in brown adipocytes is not observed in white adipocytes, in which LD and glycogen clusters are spatially separated. Further studies are needed to understand the difference in glycogen dynamics and LD formation between white and brown adipocytes.

\section{Conclusion}


Are the mechanisms involving glycogen in lipid storage during development and reacclimation during BAT activation in adults similar? Further studies are needed to answer this question. To date, there are no indications on the specific role of LDs in BAT at birth. At birth the BAT is full of LD and we have shown that this is due to the biogenesis of LD from glycogen during embryonic development. Is the same process repeated after the first exposure to cold at birth? The number and size of LDs increase during postnatal development in BAT (38) and the presence of glycogen has been described in the BAT of neonates $(26,27)$. We can hypothesize that after the first cold exposure at birth, glycogen accumulates and is involved in the replenishment of LD in BAT. Similar mechanisms are probably also recapitulated when BAT is activated in adult. New genetic models of glycogen modulation in adult brown adipocytes will allow in the future to better understand the role of glycogen in BAT physiology. More generally, the development of new conditional and inducible mouse models will help to decipher the relative contribution of fatty acids and carbohydrates in the BAT.

Figure 1

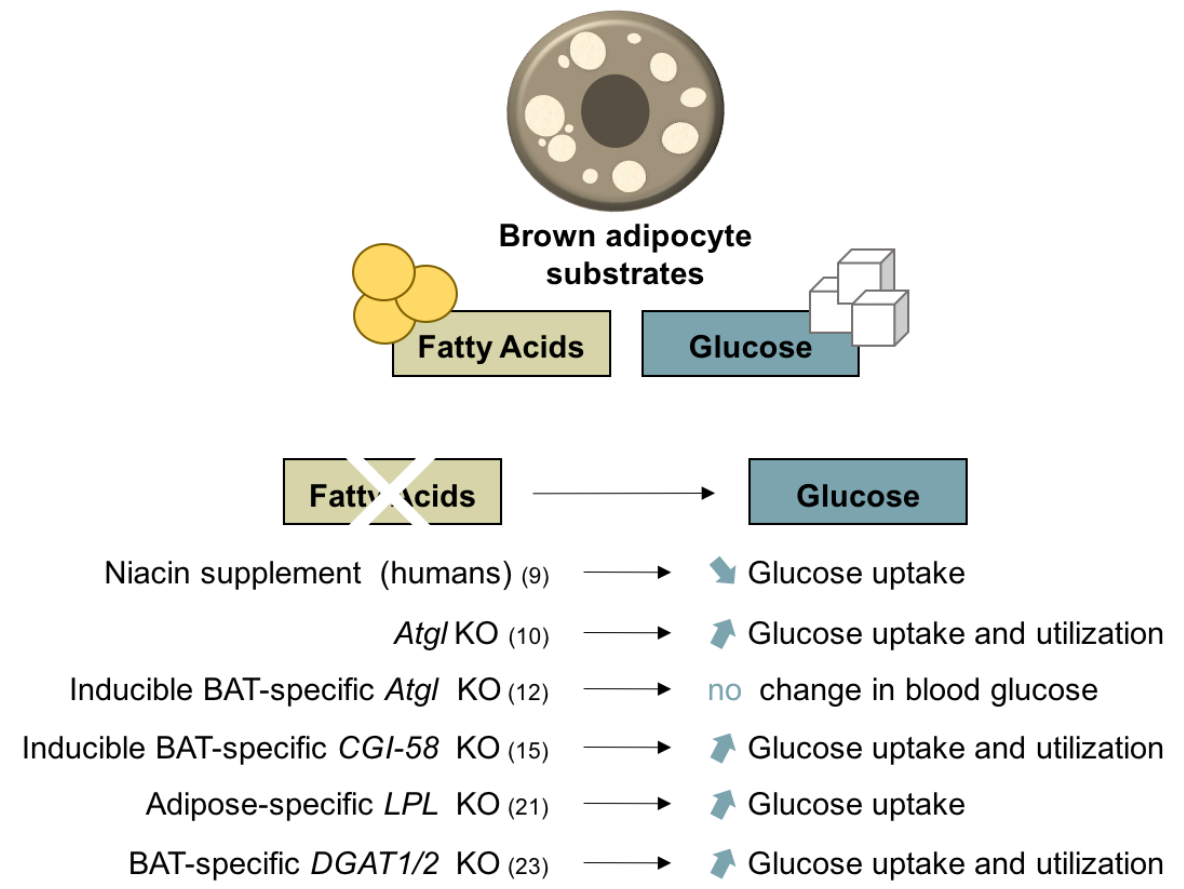


Figure 2
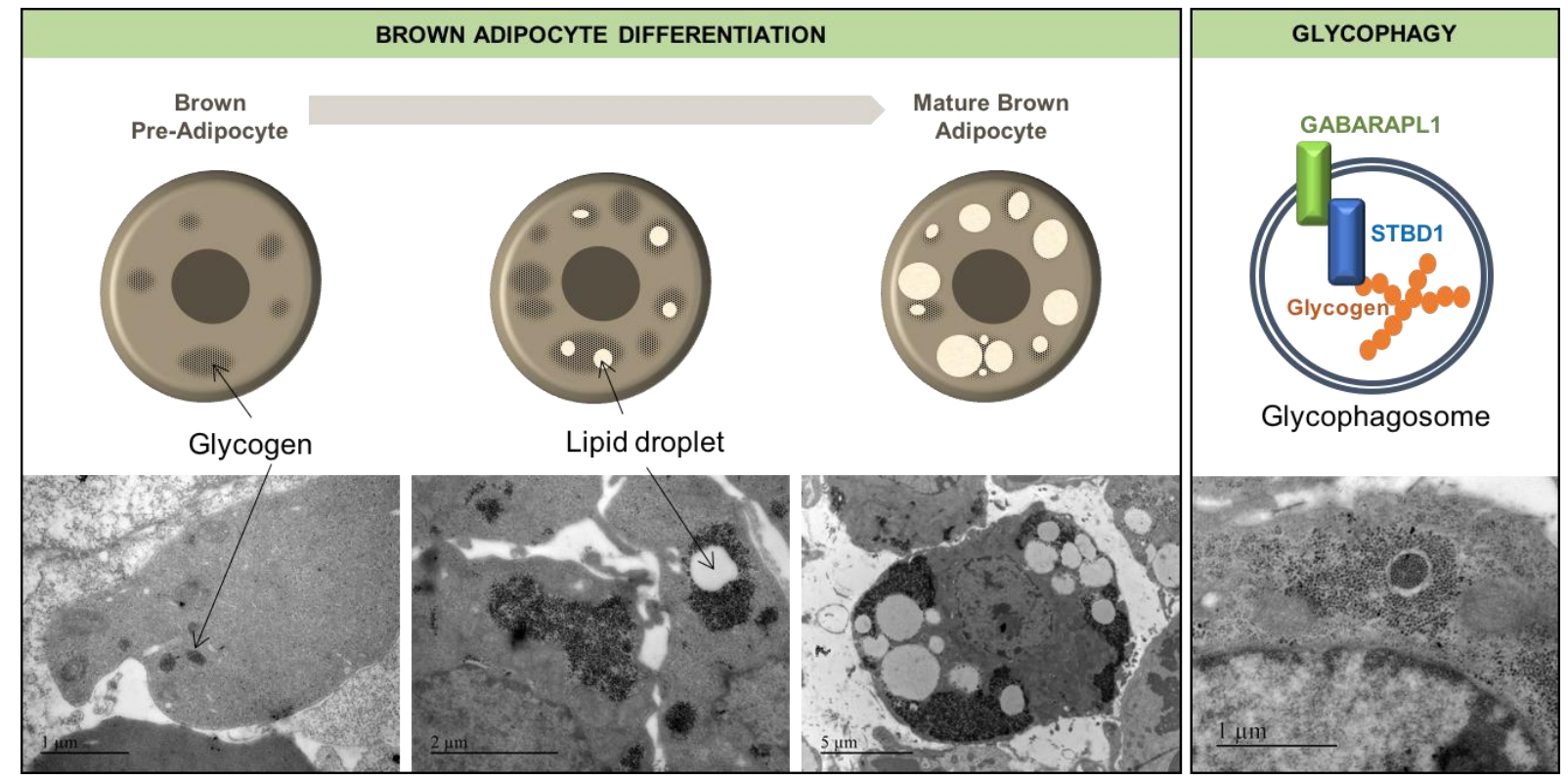

\section{Figures Legend}

Figure 1. Schematic representation of the energy substrates used by BAT and the consequences of the alteration of FA metabolism on glucose metabolism.

Figure 2. Schematic representation of brown adipocyte differentiation during embryonic development (left panel) and glycophagy (right panel). Glycogen accumulates in the brown pre-adipocytes. Lipid droplets form within the glycogen clusters and develop as the glycogen content decreases. Glycophagosomes are found inside the glycogen clusters before lipid droplets formation. Under each pattern are placed representative images of brown adipocytes by electron microscopy.

\section{Acknowledgments}


I thank Dr. Hélène Duez for her advice and critical reading of the manuscript. We acknowledge support from INSERM; the ANR-Labex-EGID (EGID, ANR-10-LABX-46); the Région Hauts-de-France/FEDER (Chronoregeneration); the Fondation de France and the Fondation Francophone pour la recherche sur le diabète (FFRD) sponsored by the Fédération Française des Diabétiques (AFD), AstraZeneca, Eli Lilly, Merck Sharp \& Dohme (MSD), and Novo Nordisk \& Sanofi. A.M.-L. was supported by the Association Française contre les Myopathies (AFM-Téléthon) and the Région Hauts-de-France/CPER CTRL (CloockMuscleAging).

\section{References}

1. Cypess AM, Lehman S, Williams G, Tal I, Rodman D, Goldfine AB, et al. Identification and importance of brown adipose tissue in adult humans. N Engl J Med. 2009 Apr 9;360(15):1509-17.

2. van Marken Lichtenbelt WD, Vanhommerig JW, Smulders NM, Drossaerts JMAFL, Kemerink GJ, Bouvy ND, et al. Cold-activated brown adipose tissue in healthy men. N Engl J Med. 2009 Apr 9;360(15):1500-8.

3. Virtanen KA, Lidell ME, Orava J, Heglind M, Westergren R, Niemi T, et al. Functional brown adipose tissue in healthy adults. N Engl J Med. 2009 Apr 9;360(15):1518-25.

4. Sanchez-Gurmaches J, Hung C-M, Guertin DA. Emerging Complexities in Adipocyte Origins and Identity. Trends Cell Biol. 2016;26(5):313-26.

5. Nishimoto Y, Tamori Y. CIDE Family-Mediated Unique Lipid Droplet Morphology in White Adipose Tissue and Brown Adipose Tissue Determines the Adipocyte Energy Metabolism. J Atheroscler Thromb. 2017 Oct 1;24(10):989-98.

6. Alexander G. Energy metabolism in the starved new-born lamb. Australian Journal of Agricultural Research. 1962;144-64.

7. Dawkins MJ, Scopes JW. Non-shivering thermogenesis and brown adipose tissue in the human new-born infant. Nature. 1965 Apr 10;206(980):201-2.

8. Bartelt A, Bruns OT, Reimer R, Hohenberg H, Ittrich H, Peldschus $\mathrm{K}$, et al. Brown adipose tissue activity controls triglyceride clearance. Nat Med. 2011 Feb;17(2):200-5.

9. Blondin DP, Frisch F, Phoenix S, Guérin B, Turcotte ÉE, Haman F, et al. Inhibition of Intracellular Triglyceride Lipolysis Suppresses Cold-Induced Brown Adipose Tissue Metabolism and Increases Shivering in Humans. Cell Metab. 2017 07;25(2):438-47.

10. Haemmerle G, Lass A, Zimmermann R, Gorkiewicz G, Meyer C, Rozman J, et al. Defective lipolysis and altered energy metabolism in mice lacking adipose triglyceride lipase. Science. 2006 May 5;312(5774):734-7.

11. Osuga J, Ishibashi S, Oka T, Yagyu H, Tozawa R, Fujimoto A, et al. Targeted disruption of hormone-sensitive lipase results in male sterility and adipocyte hypertrophy, but not in obesity. Proc Natl Acad Sci U S A. 2000 Jan 18;97(2):787-92.

12. Schreiber R, Diwoky C, Schoiswohl G, Feiler U, Wongsiriroj N, Abdellatif M, et al. 
Cold-Induced Thermogenesis Depends on ATGL-Mediated Lipolysis in Cardiac Muscle, but Not Brown Adipose Tissue. Cell Metab. 2017 Nov 7;26(5):753-763.e7.

13. Wang SP, Laurin N, Himms-Hagen J, Rudnicki MA, Levy E, Robert MF, et al. The adipose tissue phenotype of hormone-sensitive lipase deficiency in mice. Obes Res. 2001 Feb;9(2):119-28.

14. Ahmadian M, Abbott MJ, Tang T, Hudak CSS, Kim Y, Bruss M, et al. Desnutrin/ATGL is regulated by AMPK and is required for a brown adipose phenotype. Cell Metab. 2011 Jun 8;13(6):739-48.

15. Shin H, Ma Y, Chanturiya T, Cao Q, Wang Y, Kadegowda AKG, et al. Lipolysis in Brown Adipocytes Is Not Essential for Cold-Induced Thermogenesis in Mice. Cell Metab. 2017 Nov 7;26(5):764-777.e5.

16. Heine M, Fischer AW, Schlein C, Jung C, Straub LG, Gottschling K, et al. Lipolysis Triggers a Systemic Insulin Response Essential for Efficient Energy Replenishment of Activated Brown Adipose Tissue in Mice. Cell Metab. 2018 02;28(4):644-655.e4.

17. Simcox J, Geoghegan G, Maschek JA, Bensard CL, Pasquali M, Miao R, et al. Global Analysis of Plasma Lipids Identifies Liver-Derived Acylcarnitines as a Fuel Source for Brown Fat Thermogenesis. Cell Metab. 2017 Sep 5;26(3):509-522.e6.

18. Blondin DP, Nielsen S, Kuipers EN, Severinsen MC, Jensen VH, Miard S, et al. Human Brown Adipocyte Thermogenesis Is Driven by $\beta 2$-AR Stimulation. Cell Metab. 2020 Aug 4;32(2):287-300.e7.

19. Weinstock PH, Levak-Frank S, Hudgins LC, Radner H, Friedman JM, Zechner R, et al. Lipoprotein lipase controls fatty acid entry into adipose tissue, but fat mass is preserved by endogenous synthesis in mice deficient in adipose tissue lipoprotein lipase. Proc Natl Acad Sci U S A. 1997 Sep 16;94(19):10261-6.

20. Chondronikola M, Volpi E, Børsheim E, Porter C, Saraf MK, Annamalai P, et al. Brown Adipose Tissue Activation Is Linked to Distinct Systemic Effects on Lipid Metabolism in Humans. Cell Metab. 2016 Jun 14;23(6):1200-6.

21. Bartelt A, Weigelt C, Cherradi ML, Niemeier A, Tödter K, Heeren J, et al. Effects of adipocyte lipoprotein lipase on de novo lipogenesis and white adipose tissue browning. Biochim Biophys Acta. 2013 May;1831(5):934-42.

22. Martinez-Lopez N, Garcia-Macia M, Sahu S, Athonvarangkul D, Liebling E, Merlo P, et al. Autophagy in the CNS and Periphery Coordinate Lipophagy and Lipolysis in the Brown Adipose Tissue and Liver. Cell Metab. 2016 Jan 12;23(1):113-27.

23. Chitraju C, Fischer AW, Farese RV, Walther TC. Lipid Droplets in Brown Adipose Tissue Are Dispensable for Cold-Induced Thermogenesis. Cell Rep. 2020 nov 3; 33(5):108348.

24. Bhatt-Wessel B, Jordan TW, Miller JH, Peng L. Role of DGAT enzymes in triacylglycerol metabolism. Arch Biochem Biophys. 2018 01;655:1-11.

25. Mayeuf-Louchart A, Lancel S, Sebti Y, Pourcet B, Loyens A, Delhaye S, et al. Glycogen Dynamics Drives Lipid Droplet Biogenesis during Brown Adipocyte Differentiation. Cell Rep. 2019 Nov 5;29(6):1410-1418.e6.

26. Napolitano L, Fawcett D. The fine structure of brown adipose tissue in the newborn mouse and rat. J Biophys Biochem Cytol. 1958 Nov 25;4(6):685-92.

27. Revel JP, Napolitano L, Fawcett DW. Identification of glycogen in electron micrographs of thin tissue sections. J Biophys Biochem Cytol. 1960 Dec;8:575-89.

28. Hankir MK, Klingenspor M. Brown adipocyte glucose metabolism: a heated subject. EMBO Rep. 2018;19(9). 
29. McNeill BT, Morton NM, Stimson RH. Substrate Utilization by Brown Adipose Tissue: What's Hot and What's Not? Front Endocrinol. 2020;11:571659.

30. Creasey $\mathrm{NH}$, Gray $\mathrm{CH}$. Enzymes concerned in the synthesis of glycogen from glucose in the brown adipose tissue. Biochem J. 1951 Nov;50(1):74-81.

31. Farkas V, Kelenyi G, Sandor A. A dramatic accumulation of glycogen in the brown adipose tissue of rats following recovery from cold exposure. Arch Biochem Biophys. 1999 May 1;365(1):54-61.

32. Jakus PB, Sandor A, Janaky T, Farkas V. Cooperation between BAT and WAT of rats in thermogenesis in response to cold, and the mechanism of glycogen accumulation in BAT during reacclimation. J Lipid Res. 2008 Feb;49(2):332-9.

33. Tuerkischer E, Wertheimer E. Glycogen and adipose tissue. J Physiol. 1942 Mar 31;100(4):385-409.

34. Carmean CM, Bobe AM, Yu JC, Volden PA, Brady MJ. Refeeding-induced brown adipose tissue glycogen hyper-accumulation in mice is mediated by insulin and catecholamines. PloS One. 2013;8(7):e67807.

35. Carmean CM, Huang YH, Brady MJ. Glycogen Repletion in Brown Adipose Tissue upon Refeeding Is Primarily Driven by Phosphorylation-Independent Mechanisms. PloS One. 2016;11(5):e0156148.

36. Hao Q, Yadav R, Basse AL, Petersen S, Sonne SB, Rasmussen S, et al. Transcriptome profiling of brown adipose tissue during cold exposure reveals extensive regulation of glucose metabolism. Am J Physiol Endocrinol Metab. 2015 Mar 1;308(5):E380392.

37. Jiang S, Wells CD, Roach PJ. Starch-binding domain-containing protein 1 (Stbd1) and glycogen metabolism: Identification of the Atg8 family interacting motif (AIM) in Stbd1 required for interaction with GABARAPL1. Biochem Biophys Res Commun. 2011 Sep 30;413(3):420-5.

38. Liu J, Zhang C, Zhang B, Sheng Y, Xu W, Luo Y, et al. Comprehensive Analysis of the Characteristics and Differences in Adult and Newborn Brown Adipose Tissue (BAT): Newborn BAT Is a More Active/Dynamic BAT. Cells. 2020 14;9(1). 